\title{
Beliefs of South Africans regarding food and cardiovascular health
}

\author{
Robin C Dolman ${ }^{1}$, Welma Stonehouse ${ }^{1,2}$, Hilda van't Riet ${ }^{1}$, Jane Badham ${ }^{1}$ and \\ Johann C Jerling ${ }^{1, *}$ \\ ${ }^{1}$ School of Physiology, Nutrition and Consumer Science, North-West University Potchefstroom Campus, Private \\ Bag X6001, Potchefstroom 2520, Republic of South Africa: ${ }^{2}$ Institute of Food, Nutrition and Human Health, \\ Massey University, Auckland, New Zealand
}

Submitted 7 January 2007: Accepted 9 September 2007: First published online 16 November 2007

\begin{abstract}
Objectives: To investigate the beliefs of South African metropolitan adults regarding the importance of influencing cardiovascular health by eating certain food types, and to compare these beliefs between different race, living standards, age and gender groups.

Design: Randomised cross-sectional study. Trained fieldworkers administered questionnaires by conducting face-to-face interviews with consumers.

Subjects: Two thousand South Africans (16 years and older) were randomly selected from metropolitan areas in South Africa. The data were weighted to be representative of the total South African metropolitan population $(N=10695000)$ based on gender, age and race distribution.

Results: The majority (94\%) of the population indicated that it is important to influence cardiovascular risk-related health issues by eating certain food types, especially the higher LSM (Living Standard Measure) groups within the different race groups. Weight loss was considered the least important (61\% indicated that it is important) compared with cholesterol lowering (80\%), blood pressure (89\%), diabetes (86\%) and healthy blood vessels (89\%). In the higher LSM groups (7-10) higher proportions of respondents agreed than in the lower LSM groups (2 and 3). No differences were seen in responses between different gender, race and age groups.

Conclusions and recommendations: This study shows that the metropolitan South African adult population considers the influence on cardiovascular health by eating certain food types to be important. However, modifying weight loss by eating certain food types was considered less important.
\end{abstract}

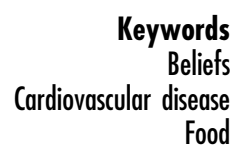

The World Health Organization attributes one-third of all global deaths $\left(15 \cdot 3\right.$ million) to coronary heart disease ${ }^{(1)}$. South Africa is a country with great diversity in race as well as economic status. The country has highly industrialised cities which follow a predominantly urban Western culture, as well as remote rural areas where many South Africans still follow traditional African lifestyles ${ }^{(2)}$. This diverse country has a high overall prevalence of cardiovascular disease (CVD), although it differs significantly between the various ethnic groups. CVD is the second leading cause of death (due to disease) in South Africa, at $16.6 \%{ }^{(3)}$. It is still rare among rural blacks, although the prevalence may be on the rise among urban blacks $^{(4)}$. Stroke is the most important non-communicable disease in females and ischaemic heart disease in males. Hypertensive heart disease is also a major cause of premature death in females ${ }^{(3)}$. Deaths from non-communicable disease increase from the age of 45 years in South African males and females ${ }^{(3)}$.

Dietary interventions, together with other lifestyle changes, form an essential part of the prevention and treatment of CVD and CVD risk factors ${ }^{(5)}$. Numerous large, randomised, controlled clinical trials have proved the importance of diet in $\mathrm{CVD}^{(6)}$.

South Africa has its own dietary guidelines for the prevention and management of dyslipidaemia ${ }^{(7)}$. In addition, the South African Food-Based Dietary Guidelines are aimed at helping South Africans choose an adequate and prudent diet in a positive, practical, affordable, sustainable and culturally acceptable way ${ }^{(8)}$. The Heart Foundation of Southern Africa was established in 1981 and is a community-based health organisation established to reduce the incidence of heart disease and stroke in the South African population by providing 
education and supporting research ${ }^{(9)}$. The Heart Foundation's Heart Mark symbol, for example, is an incentive for consumers to easily identify heart-healthy products, as these foods are lower in cholesterol, saturated fat, salt and added sugar, and higher in fibre ${ }^{(10)}$.

Consumers' beliefs on the importance of the link between the foods they eat and CVD may influence their behaviour and health practice. Factors such as race, age, gender and socio-economic status may, furthermore, influence consumers' beliefs. According to Sargeant and West $^{(11)}$, an attitude, in consumer behaviour terms, is a lasting, general evaluation of products and ideas. Attitudes are formed by personal usage or trust in the attitudes of other influential users, while beliefs may be formed without product experience ${ }^{(11)}$. A study of black South African university students showed that beliefs were more independent predictors of health behaviours than was risk awareness ${ }^{(12)}$. Studies have also shown that the perceived advantages of certain health behaviours are associated with actual practice of such behaviours $^{(13)}$. For prevention programmes to be effective, it is important for health promotion advice to be culturally sensitive and relevant for the target population $^{(14)}$. It is therefore important that the beliefs of specific target groups regarding food and health are taken into account when planning primary prevention programmes.

Functional foods are one of the major trends in the food industry in this new millennium ${ }^{(15)}$ and they are believed to play a major role in maintaining health and preventing disease ${ }^{(16)}$. Consumers' beliefs about the importance of influencing health by eating certain food types may give important direction for the food industry when formulating new functional food products, especially regarding potential target groups.

The present investigation, the first of its kind in South Africa, aimed to investigate the beliefs of South African adults living in the metropolitan areas of the country about the importance of influencing cardiovascular health by eating certain food types. More specifically, differences in beliefs towards food and cardiovascular health between the different races, living standards, age and gender groups were investigated. Additionally, differences in living standards, gender and age were investigated within different ethnic groups. It was also determined how important the link between food and heart disease is believed to be compared with other highly prevalent diseases in South Africa such as HIV/ AIDS, the main cause of death (30\%), and cancer, the fourth major cause of death $(7.5 \%)^{(3)}$. Finally, the study also aimed to determine whether this population looks for the Heart Foundation symbol on food products or not. This study forms part of a larger study which investigated South African consumers' opinions and perceptions on a number of food- and health-related topics.

\section{Methods}

\section{Subjects}

Two thousand South African individuals (16 years and older), randomly selected from metropolitan areas in South Africa, participated in this survey. The metropolitan areas were described as Gauteng, Pretoria, Durban/ Pietermaritzburg, Port Elizabeth/East London, Bloemfontein and Cape Town. It included squatters but excluded live-in domestic workers and hostel dwellers. Owing to incomplete data, three respondents' data were excluded from the analysis resulting in a total number of 1997 respondents. The random sample was weighted using cell weighing of the 1996 census data of Statistics South Africa, to reflect the projected adult metropolitan population based on gender, age and race distribution of the year $2000^{(17)}$. This means that the respondents represent a total metropolitan population of 10695000. The study population was representative of both genders ( 5423000 men and 5272000 women) and major race groups (2615000 whites, 6252000 blacks, 1255000 coloureds (people of mixed ancestry) and 573000 Indians) from different age and living standards groups.

\section{Study design}

A randomised cross-sectional study design was used. The market research company MARKINOR (Randburg, South Africa) was contracted to do the random selection and collection of the data. The sample was stratified by province and, within province, by community size, city, township and suburb. Within each stratum, sampling points were determined by systematic random selection, based on cumulative population figures per group. A starting point per sample point was randomly selected. A low integer point was randomly selected and the first interview took place at the house with the lowest number ending in the low integer. From this starting point every third household was chosen until a cluster of five was completed. When there was more than one household on a stand, one was randomly selected. Within a household all qualifying members were listed and the qualifying respondent determined by a random selection grid. All efforts were made to interview this person. If this proved impossible even after three calls, including weekend and evening calls or if the person refused to participate, someone of the same gender, age and working status living in the same street substituted the person.

Contracted trained fieldworkers with at least secondary school (12 years) education administered questionnaires by conducting face-to-face interviews in the homes, in the language of the respondent's choice (English, Afrikaans, Xhosa, Zulu, Tswana, North Sotho or South Sotho). The base language of the questionnaire was English. It was 
then translated from the base language by a translator whose native language was the one into which the questionnaire was being translated. Someone whose native language was English then translated this version back into English. In this way translation errors could be identified and corrected. A minimum of $20 \%$ back-check on each interviewer's work, either by a personal visit or telephone call, was made by the team supervisor to ensure further reliability and validity of data.

The fieldworkers were also issued with 'show cards' to aid them in ensuring that the participants fully understood the question being asked. The show cards explained the scale for the way in which questions were to be answered, as well as complex or foreign terms. For example, the question about cholesterol levels was explained as 'Preventing excess fat in the blood, which may clog the blood vessels'. The question about heart disease was explained on the show card as 'Making sure that your heart is kept healthy and preventing heart attacks'.

\section{Questionnaires}

A multidisciplinary team consisting of marketers, dietitians, nutritionists and research specialists designed the questionnaires. Seventeen food- and health-related questionnaires (with a number of subsections) were developed. Demographic information such as race, gender, age and information to determine the Living Standard Measure (LSM) were collected. The South African Advertising Research Foundations' (SAARF) classification to group people according to their living standards using criteria such as degree of urbanisation and ownership of cars and major appliances was used. The SAARF LSM divides the population into 10 groups, from LSM group 1 at the bottom end to LSM group 10 at the top end ${ }^{(18)}$. There were no people in LSM group 1 living in the metropolitan areas.

Face validity was addressed by compiling the measuring instrument in such a way that it not only measured the topics under consideration as accurately as possible, but also appeared to be a relevant measure of the topics investigated $^{(19)}$. The panel agreed on the adequacy of the questions investigating the food-and health-related topics applicable to this study which, according to Babbie and Mouton $^{(20)}$, is an indication of the face validity of the questionnaire.

To meet the specific objectives of this part of the larger study, the following statements (questions) were selected from the original questionnaires.

If you could influence the following health issues by eating certain food types, indicate how important each bealth issue would be to you:

1. Heart disease

2. Weight loss

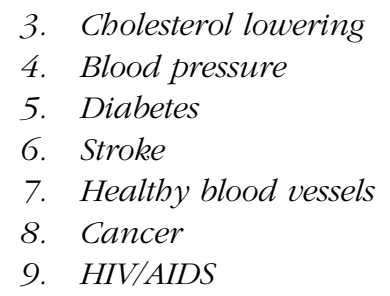

Respondents were asked to rate how important each health issue would be to them on a 5-point Likert response scale: don't know $=6$; very important $=5$; important $=4$; neither important nor unimportant $=3$; unimportant $=2$; very unimportant $=1$. 'Don't know' was never offered as a possibility but was coded if the subjects indicated that they did not know.

The following question was included to test whether respondents were aware of the South African Heart Foundation symbol:

Indicate to what extent you agree or disagree with the following statement:

I look for the Heart Foundation symbol

Respondents were asked to rate the above statement on how strongly they agreed with it on a 5-point Likert response scale: don't know $=6$; strongly agree $=5$; agree $=4 ;$ neither agree nor disagree $=3 ;$ disagree $=2$; strongly disagree $=1$.

\section{Statistical analysis}

The computer software package Statistica ${ }^{\circledR}$ Release 6 (Statsoft Inc., Tulsa, OK, USA) was used to perform the statistical analysis. The weighted data were used for all the statistical analyses to reflect the total metropolitan population. Subjects who answered 'don't know' to any of the statements were treated as missing values.

Cross-tabulations were carried out for the individual statements to calculate the frequencies of responses of the study population and the following subgroups: race, gender, age ( $<45$ and $\geq 45$ years) and LSM groups. The specific age groups were used because, according to Bradshaw et al. $^{(3)}$, deaths from non-communicable diseases start increasing from the age of 45 years. Crosstabulations were used to describe the study population's demographic profile. Means and standard deviations (SD) of selected statements were calculated.

Construct validity is concerned with the meaning of the instrument $^{(19)}$, and was investigated by performing item and factor analysis using principal components on the results of the seven statements (excluding HIV/AIDS and cancer) and using it as a scale for beliefs regarding food and CVD. All seven statements, except the one on weight loss, were included in the scale. The scale was named the 'CVD scale'. A few factors that together explain a substantial proportion of the variance and high communalities on each item (which were obtained for this study) are good indications of construct validity. 
The percentage variation explained by the scale was $53.1 \%$, indicating good validity. Another measure for reliability used in this study was the computing of Cronbach alpha coefficients and a value of 0.81 was found, indicating excellent reliability ${ }^{(21)}$.

One-way analysis of variance was performed to test for significant differences between mean responses of different race, gender age and LSM groups. In addition, within each race group, significant differences between mean responses of different gender, age and LSM groups were determined. In cases where there were more than two categories (race and LSM groups), post hoc comparisons were done to determine which means differed statistically significantly from each other by using the HSD test for unequal $N$. A small $P$ value $(<0.05)$ is usually considered as statistically significant. However, statistical significance does not necessarily imply that the result is important in practice, especially when very large data sets are used. Ellis and Steyn ${ }^{(22)}$ reported that statistical significance tests have a tendency to yield small $P$ values as the size of the data sets increases. They state that the effect size is independent of sample size and is a measure of practical significance. In other words, it determines whether the effect is large enough to be important in practice. Because of this study's large sample size, randomly selected from the South African metropolitan population, only practical significance between means is reported.

Practical significance was calculated by using the standardised difference between the two means divided by the estimate for standard deviation. An effect size
( $d$ value) of $<0.5$ was considered as a small effect and $d \geq 0.5$ as a practical significant effect.

\section{Results}

The demographic profile of the total population is summarised in Table 1 . Most of the white population is classified as part of the higher LSM categories (9 and 10), and the black population as part of the lower LSM categories (3-6). Both coloured and Indian populations range mainly in between (LSM 5-8).

Although all the statistical analyses were performed on the 5-point Likert response scales, for practical reasons the results are reported as 'important' and 'unimportant', which were obtained by combining 'very important' with 'important' and 'unimportant' with 'very unimportant'. Likewise for the second scale, where the results are reported as 'agree' and 'disagree' obtained by combining respectively 'strongly agree' with 'agree' and 'strongly disagree' with 'disagree'. As discussed in the Methods section, only practical significant differences of statistically significant results are reported.

The percentage of subjects, stratified for gender, age, race and LSM group, who indicated that they considered the influence on cardiovascular health by eating certain food types as important are summarised in Table 2. No practical significant differences $(d<0.5)$ were seen between gender, race, age or LSM groups, except with regard to healthy blood vessels where coloured subjects considered it more important than white subjects.

Table 1 Characteristics of the total population $(N=10695000)^{\star}$

\begin{tabular}{|c|c|c|c|c|c|c|c|c|}
\hline \multirow[b]{2}{*}{ Variable } & \multicolumn{2}{|c|}{ Total group } & \multicolumn{2}{|c|}{ Gender } & \multicolumn{4}{|c|}{ Race } \\
\hline & Number & $\%$ & Men & Women & White & Black & Coloured & Indian \\
\hline \multicolumn{9}{|l|}{ Gender } \\
\hline Men & 5423000 & 50.7 & & & 1295000 & 3261000 & 588000 & 279000 \\
\hline Women & 5272000 & $49 \cdot 3$ & & & 1320000 & 2991000 & 667000 & 294000 \\
\hline \multicolumn{9}{|l|}{ Age group } \\
\hline$<45$ years & 7718000 & $72 \cdot 2$ & 3985000 & 3733000 & 1482000 & 4915000 & 938000 & 383000 \\
\hline$\geq 45$ years & 2977000 & $27 \cdot 8$ & 1438000 & 1539000 & 1133000 & 1337000 & 317000 & 190000 \\
\hline \multicolumn{9}{|l|}{ Race } \\
\hline White & 2615000 & 24.5 & 1295000 & 1320000 & & & & \\
\hline Black & 6252000 & 58.5 & 3261000 & 2991000 & & & & \\
\hline Coloured & 1255000 & 11.7 & 588000 & 667000 & & & & \\
\hline Indian & 573000 & 5.4 & 279000 & 294000 & & & & \\
\hline \multicolumn{9}{|l|}{ LSM group } \\
\hline LSM 2 & 408000 & 3.8 & 177000 & 231000 & 0 & 408000 & 0 & 0 \\
\hline LSM 3 & 671000 & $6 \cdot 3$ & 364000 & 307000 & 4000 & 661000 & 6000 & 0 \\
\hline LSM 4 & 1346000 & $12 \cdot 6$ & 649000 & 697000 & 0 & 1328000 & 14000 & 4000 \\
\hline LSM 5 & 2336000 & 21.8 & 1230000 & 1106000 & 20000 & 2084000 & 200000 & 32000 \\
\hline LSM 6 & 1967000 & 18.4 & 1129000 & 838000 & 112000 & 1314000 & 431000 & 110000 \\
\hline LSM 7 & 849000 & 7.9 & 360000 & 489000 & 214000 & 317000 & 174000 & 144000 \\
\hline LSM 8 & 799000 & 7.5 & 387000 & 412000 & 316000 & 123000 & 244000 & 116000 \\
\hline LSM 9 & 994000 & 9.3 & 487000 & 507000 & 762000 & 17000 & 130000 & 85000 \\
\hline LSM 10 & 1325000 & 12.4 & 640000 & 685000 & 1187000 & 0 & 56000 & 82000 \\
\hline
\end{tabular}

LSM, Living Standard Measure.

${ }^{*}$ Weighted data based on interviews with 1997 respondents. 
Table 2 South African metropolitan adults who indicated that they consider it to be important to influence cardiovascular health by eating certain food types and that they look for the Heart Foundation symbol (\%)

\begin{tabular}{|c|c|c|c|c|c|c|c|c|c|c|c|c|c|c|c|c|}
\hline \multirow[b]{2}{*}{ Variable } & \multicolumn{2}{|c|}{ Heart disease } & \multicolumn{2}{|c|}{ Weight loss } & \multicolumn{2}{|c|}{ Cholesterol lowering } & \multicolumn{2}{|c|}{ Blood pressure } & \multicolumn{2}{|c|}{ Diabetes } & \multicolumn{2}{|c|}{ Stroke } & \multicolumn{2}{|c|}{$\begin{array}{l}\text { Healthy blood } \\
\text { vessels }\end{array}$} & \multicolumn{2}{|c|}{$\begin{array}{c}\text { Heart Foundation } \\
\text { symbol }^{*}\end{array}$} \\
\hline & Un & Im & Un & Im & Un & Im & Un & Im & Un & Im & Un & Im & Un & Im & Dis & Agr \\
\hline \multicolumn{17}{|l|}{ Gender } \\
\hline Male & $4 \cdot 3$ & $93 \cdot 4$ & $24 \cdot 1$ & $57 \cdot 3$ & $6 \cdot 2$ & 79.4 & 4.5 & 89.0 & $6 \cdot 1$ & 85.5 & $6 \cdot 7$ & $85 \cdot 9$ & 3.8 & $88 \cdot 8$ & $48 \cdot 1$ & $32 \cdot 4$ \\
\hline Female & 3.7 & $93 \cdot 6$ & $17 \cdot 6$ & 65.6 & $6 \cdot 8$ & 80.5 & 4.8 & 89.2 & $7 \cdot 6$ & 85.7 & $6 \cdot 0$ & 86.5 & 3.7 & 88.4 & $43 \cdot 2$ & $37 \cdot 6$ \\
\hline \multicolumn{17}{|l|}{ Race } \\
\hline White & 2.4 & 94.3 & 17.4 & 60.7 & 5.3 & 83.6 & $6 \cdot 0$ & 83.7 & $10 \cdot 8$ & 75.7 & $10 \cdot 2$ & 79.0 & $5 \cdot 3$ & $83.6^{a}$ & 33.3 & $42 \cdot 6$ \\
\hline Black & 5.4 & 92.4 & 23.8 & 59.2 & $7 \cdot 2$ & 76.4 & 4.1 & 90.1 & $5 \cdot 2$ & 88.5 & 5.2 & 88.3 & 3.3 & 89.5 & 51.4 & 29.4 \\
\hline Coloured & $2 \cdot 2$ & 95.2 & 14.5 & $72 \cdot 8$ & $6 \cdot 3$ & $86 \cdot 1$ & 6.5 & $92 \cdot 3$ & 8.5 & 89.5 & 4.7 & $90 \cdot 1$ & $2 \cdot 6$ & $95.0^{\mathrm{b}}$ & 43.7 & $41 \cdot 6$ \\
\hline Indian & 0 & 98.4 & 19.7 & 63.7 & $6 \cdot 3$ & $86 \cdot 2$ & 0 & 95.8 & $2 \cdot 8$ & 89.9 & 5.4 & $88 \cdot 1$ & 4.7 & 87.4 & 44.4 & $46 \cdot 0$ \\
\hline \multicolumn{17}{|l|}{ Age group } \\
\hline$<45$ years & 4.7 & $92 \cdot 6$ & 19.9 & 63.6 & 7.8 & 78.7 & $5 \cdot 2$ & 88.2 & $7 \cdot 3$ & $85 \cdot 3$ & $7 \cdot 1$ & $85 \cdot 2$ & 4.2 & 88.4 & 46.9 & $32 \cdot 7$ \\
\hline$\geq 45$ years & 2.1 & $96 \cdot 0$ & 23.4 & 55.8 & 3.3 & 83.0 & $3 \cdot 2$ & 91.4 & 5.8 & $86 \cdot 3$ & 4.6 & 88.7 & 2.7 & 89.2 & $42 \cdot 6$ & $41 \cdot 0$ \\
\hline \multicolumn{17}{|l|}{ LSM group } \\
\hline LSM 2 & $10 \cdot 8$ & 87.5 & 23.8 & $56 \cdot 1$ & 0.1 & 73.8 & $5 \cdot 2$ & 88.6 & $3 \cdot 2$ & 91.5 & $5 \cdot 3$ & 89.6 & 3.6 & 83.0 & 65.1 & $18 \cdot 9^{\mathrm{a}}$ \\
\hline LSM 3 & 2.5 & 94.3 & 24.4 & 48.4 & 8.2 & 68.6 & 6.4 & 85.0 & $5 \cdot 1$ & 84.8 & $6 \cdot 3$ & 84.8 & 3.0 & 84.6 & 62.6 & $23.5^{\mathrm{acd}}$ \\
\hline LSM 4 & 5.7 & 91.7 & 21.6 & $60 \cdot 7$ & $6 \cdot \overline{3}$ & $77 \cdot 3$ & $3 \cdot 2$ & 91.2 & 4.2 & 90.2 & 3.9 & 87.5 & 4.4 & 88.6 & 52.8 & 31.9 \\
\hline LSM 5 & 4.0 & 94.4 & $24 \cdot 8$ & 57.0 & $8 \cdot 2$ & $74 \cdot 2$ & 3.0 & $90 \cdot 8$ & 4.8 & 89.1 & 4.8 & $90 \cdot 1$ & $2 \cdot 8$ & $90 \cdot 3$ & 48.8 & 31.7 \\
\hline LSM 6 & 4.0 & 93.4 & 21.6 & $66 \cdot 9$ & 7.4 & 83.7 & $6 \cdot 1$ & 89.7 & 8.4 & 85.8 & $7 \cdot 6$ & 85.7 & 3.6 & $92 \cdot 1$ & 46.5 & 33.6 \\
\hline LSM 7 & 3.8 & 94.6 & 21.5 & $66 \cdot 6$ & 6.6 & 79.4 & 3.4 & 91.6 & 7.5 & $86 \cdot 1$ & $6 \cdot 0$ & 88.7 & 4.0 & 89.5 & 48.7 & $36 \cdot 1^{\text {bd }}$ \\
\hline LSM 8 & 3.0 & 92.7 & 17.4 & 65.4 & 6.7 & $86 \cdot 3$ & $5 \cdot 8$ & 89.0 & $6 \cdot 4$ & 86.5 & 4.7 & 85.0 & $6 \cdot 4$ & 85.5 & 34.0 & $37 \cdot 7^{\mathrm{b}}$ \\
\hline LSM 9 & 1.8 & 96.5 & 15.5 & 57.3 & 3.5 & 84.6 & $5 \cdot 2$ & 84.5 & 11.5 & 74.1 & $8 \cdot 1$ & 83.1 & 2.9 & $86 \cdot 1$ & 31.5 & $46 \cdot 8^{b}$ \\
\hline LSM 10 & 3.2 & 93.0 & $15 \cdot 6$ & 67.4 & 5.7 & 86.9 & $5 \cdot \overline{5}$ & 87.4 & 9.1 & 80.4 & $10 \cdot 1$ & 80.1 & 4.5 & 87.3 & 33.4 & $45 \cdot 2^{\mathrm{b}}$ \\
\hline
\end{tabular}

Un, unimportant; Im, important; Dis, disagree; Agr, agree; LSM, Living Standard Measure.

a,b,c,d Percentages within a column with unlike superscript letters, within the different belief categories, were different from each other with a practical significance of $d>0.5$. 
In general, the majority of the population found the link between food and cardiovascular risk-related health issues to be either important or very important. The statement with the highest average response for importance was 'Heart disease' (93.5\%), the lowest being 'Weight loss' (61.4\%). The statements of most importance to the Indian population were 'Heart disease' (98.4\%) and 'Blood pressure' (95.8\%), with 'Weight loss' (63.7\%) being the least important of the risk factors. In the white population, 'Heart disease' (94.3\%) was the most important and 'Weight loss' (60.7\%) the least important. The black population reported 'Heart disease' (92.4\%) and 'Blood pressure' (90.1\%) to be the most important with 'Weight loss' (59.2\%) the least important. 'Heart disease' (95.2\%) and 'Healthy blood vessels' (95.0\%) were the most important in the coloured population whereas 'Weight loss' (72.8\%) was the least important. With regard to the 'Weight loss' statement, the coloured population had the highest percentage of people finding this important at $72.8 \%$ with the black population being the lowest at $59 \cdot 2 \%$.

Regarding the respondents' responses to 'Looking for the Heart Foundation symbol', only $34.9 \%$ of South Africans agreed with the statement while $45.7 \%$ disagreed with the statement. The highest percentage of respondents agreeing with the statement was found within the Indian population $(46.0 \%)$ and the lowest among the black population (29.4\%). Practical significance was found between the various LSM groups as illustrated in the last column of Table 2. There were practical significant differences between LSM 2 and LSM 7, 8, 9 and 10, where in LSM 2 a much smaller percentage (18.9\%) of the study population agreed with the statement compared with between 36.1 and $46.8 \%$ in LSM groups 7 to 10 . Similarly, a practically significant smaller percentage of respondents (23.5\%) in LSM 3 agreed with the statement compared with LSM groups 8, 9 and 10. Thus, there was a greater tendency for the higher LSM groups to look for the Heart Foundation symbol than the lower LSM groups.

The means (SD) and practical significant differences in responses regarding the importance of influencing heart disease by eating certain food types between gender, age and LSM groups, within different race groups, are summarised in Table 3.

Gender and age groups did not differ practically significantly within race groups. Practical significant differences were found only between LSM groups, in particular between the lower and higher LSM groups within all four race groups. In the white population group, LSM 3 (the lowest LSM group in this population) differed in terms of practical significance from all other LSM groups, with LSM 3 finding the statement most important. In contrast, the subsequent LSM group (LSM 5) differed with practical significance from LSM 6, 7, 8, 9 and 10, with LSM 5 finding the statement least important.
Table 3 Responses regarding the importance of influencing heart disease by eating certain food types, stratified for race group $\left(\right.$ mean $^{*}$, standard deviation (SD) and practical significant differences)

\begin{tabular}{|c|c|c|c|c|c|c|c|c|}
\hline \multirow[b]{2}{*}{ Variable } & \multicolumn{2}{|c|}{ White } & \multicolumn{2}{|c|}{ Black } & \multicolumn{2}{|c|}{ Coloured } & \multicolumn{2}{|c|}{ Indian } \\
\hline & Mean & SD & Mean & SD & Mean & $\mathrm{SD}$ & Mean & SD \\
\hline \multicolumn{9}{|l|}{ Gender } \\
\hline Male & 4.5 & 0.7 & 4.5 & 0.8 & 4.7 & 0.5 & 4.6 & 0.6 \\
\hline Female & 4.6 & 0.7 & 4.5 & 0.8 & 4.6 & 0.7 & 4.7 & 0.5 \\
\hline \multicolumn{9}{|l|}{ Age group } \\
\hline$<45$ years & 4.5 & 0.7 & 4.5 & 0.9 & 4.7 & 0.6 & 4.7 & 0.5 \\
\hline$\geq 45$ years & 4.6 & 0.6 & 4.6 & 0.7 & 4.7 & 0.6 & 4.6 & 0.5 \\
\hline \multicolumn{9}{|l|}{ LSM group } \\
\hline LSM 2 & - & & $4.4^{\mathrm{a}}$ & 1.0 & - & & - & \\
\hline LSM 3 & $5.0^{\mathrm{a}}$ & 0.0 & $4 \cdot 5^{\mathrm{a}}$ & 0.7 & $5 \cdot 0^{\mathrm{a}}$ & 0.0 & - & \\
\hline LSM 4 & - & & $4.6^{\mathrm{a}}$ & 0.9 & $4.0^{\mathrm{b}}$ & 0.0 & $4.0^{\mathrm{a}}$ & 0.0 \\
\hline LSM 5 & $4.0^{\mathrm{b}}$ & 0.7 & $4 \cdot 6^{\mathrm{a}}$ & 0.8 & $4 \cdot 5^{\mathrm{c}}$ & 0.7 & $4 \cdot 4^{\mathrm{b}}$ & 0.5 \\
\hline LSM 6 & $4.5^{c}$ & 0.6 & $4.5^{\mathrm{a}}$ & 0.8 & $4 \cdot 6^{\mathrm{cd}}$ & 0.7 & $4.7^{c}$ & 0.5 \\
\hline LSM 7 & $4.5^{\mathrm{c}}$ & 0.5 & $4 \cdot 5^{\mathrm{a}}$ & 0.9 & $4 \cdot 7^{\mathrm{cd}}$ & 0.6 & $4 \cdot 7^{c}$ & 0.5 \\
\hline LSM 8 & $4 \cdot 5^{\mathrm{c}}$ & 0.6 & $4 \cdot 2^{\mathrm{a}}$ & 1.0 & $4 \cdot 8^{\mathrm{ad}}$ & 0.5 & $4 \cdot 7^{\mathrm{C}}$ & 0.5 \\
\hline LSM 9 & $4 \cdot 6^{\mathrm{c}}$ & 0.6 & $5 \cdot 0^{\mathrm{b}}$ & 0.0 & $4.9^{\text {ad }}$ & 0.6 & $4 \cdot 7^{\mathrm{c}}$ & 0.5 \\
\hline LSM 10 & $4.5^{\mathrm{c}}$ & 0.8 & - & & $4 \cdot 7^{\mathrm{cd}}$ & 0.5 & $4 \cdot 5^{\mathrm{bc}}$ & 0.6 \\
\hline
\end{tabular}

LSM, Living Standard Measure.

$a, b, c, d$ Mean values within a column with unlike superscript letters, within the different race groups, were different from each other with a practical significance of $d>0.5$.

${ }^{*}$ Mean score on 5-point Likert scale.

The same trend was seen in the coloured population: the lowest LSM group (LSM 3) found the statement most important and differed with practical significance from LSM groups 4, 5, 6, 7 and 10, while LSM 4, in contrast, found the statement least important and differed with practical significance from LSM groups 5, 6, 7, 8, 9 and 10. Furthermore, LSM 5 found the statement practically significantly less important compared with LSM 8 and 9.

In the black population LSM 9 found the statement most important and this group differed with practical significance from LSM groups 2-8, with LSM 8 finding the statement least important. In the same context as noted above, the higher LSM groups in the black population had the least number of respondents $(0 \cdot 3 \%$ and $2 \cdot 0 \%$ in LSM groups 9 and 8 of the black population).

In the Indian population, the lowest LSM group was group 4 (containing $0.7 \%$ of the Indian population); this group found the statement least important and differed with practical significance from all the other LSM groups. The mean value in LSM group 5 (containing $5.6 \%$ of the Indian population) was also significantly lower compared with LSM groups 6, 7, 8 and 9. Thus, there was a trend in the Indian population for the lower LSM groups to find the statement less important than the higher LSM groups. When excluding the lowest LSM group in the coloured population the same trend could be seen. There was no obvious trend in the white and black populations.

Differences in beliefs regarding the link between food and cardiovascular health using the CVD scale (the scale is described under Statistical methods) between gender, age and LSM groups within the different race groups were also analysed. Similar results as in the above discussion of 
Table 3 were seen (data not shown). In the white population LSM 3 and 5 reported practically significantly lower responses compared with LSM 10. LSM 5 also reported practically significantly lower responses compared with LSM 7, 8 and 9. In the black population group, the highest LSM group was 9, which reported practically significantly higher values compared with all the other LSM groups (LSM 2-8). In the coloured population group, LSM 4 had practically significantly lower responses than LSM 3, 7, 8, 9 and 10. In the Indian population group LSM 4 had practically significantly lower responses compared with LSM groups 5, 6 and 10, and LSM 5 also had practically significantly lower responses compared with LSM groups 8 and 9. Thus, the results from the link between food and the CVD scale show a trend in all four race groups for the lower LSM groups to find the statement less important than the higher LSM groups.

Figure 1 compares the beliefs regarding the importance of influencing coronary heart disease by eating certain food types with those for other prevalent diseases, namely HIV/AIDS and cancer. In the white population group the belief that heart disease (94.3\%) and cancer (91.0\%) can be influenced by eating certain food types were both considered very important, with heart disease being ranked slightly higher than cancer. The white population considered the influence of food on HIV/ AIDS less important than the other population groups. In the black and coloured populations, the results were very similar. The influence of eating certain food types on all three diseases were of great importance to them, with heart disease being ranked slightly higher than the other two diseases. The Indian population found the influence of food on heart disease (98.4\%) and cancer (99.0\%) both extremely important, with HIV/AIDS only at $81.0 \%$.

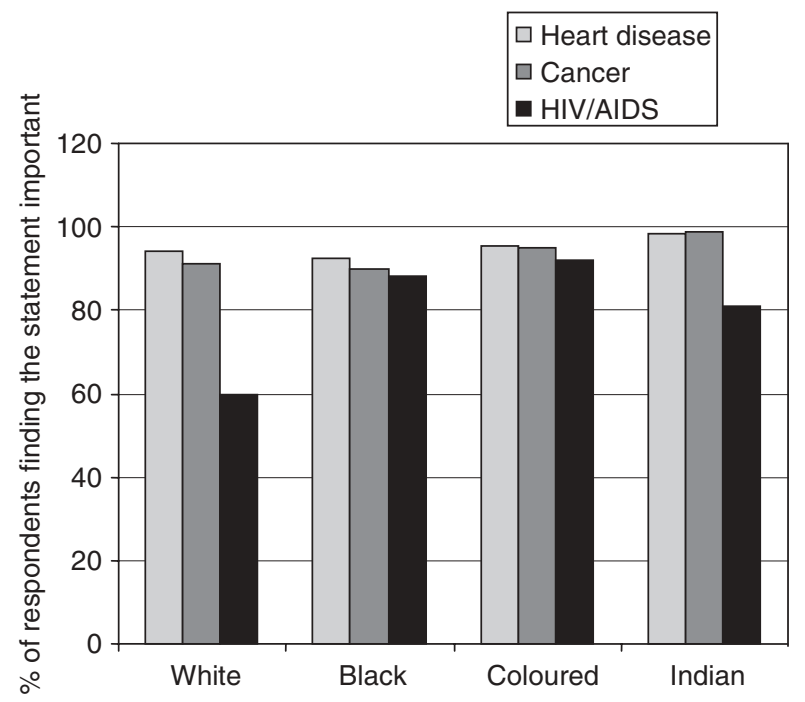

Fig. 1 Importance of the link between food and some diseases in different race groups

\section{Discussion}

The present study aimed to investigate beliefs of South African adults, living in the metropolitan areas of the country, about the importance of influencing cardiovascular health by eating certain food types. More specifically, differences in beliefs towards food and cardiovascular health between the different races, living standards, age and gender groups were investigated. A randomised cross-sectional study design with questionnaires was used and the results were extrapolated to the total South African metropolitan adult population.

The majority of the study population $(>80 \%)$ of all races, age groups, gender and LSM groups considered the influence of eating certain food types on CVD and some of its risk factors (cholesterol, blood pressure, diabetes and healthy blood vessels) to be 'important' or 'very important'. Additionally, compared with other highly prevalent diseases in South Africa, such as HIV/AIDS and cancer, the belief that CVD can be influenced by eating certain food types ranked higher in terms of importance in the white and black population groups and equally important in the Indian and coloured population groups. This finding, combined with the fact that CVD is the second leading cause of death (due to disease) in South Africa at $16.6 \%{ }^{(3)}$, should have a positive effect on motivation of individuals for participation in food programmes aimed at the prevention of CVD in this country.

In the Indian population the higher LSM groups found the link between food and heart disease more important than the lower LSM groups, whereas no clear trends could be seen in LSM groups in the white, black and coloured population groups. It should be noted that the lower LSM groups in white and coloured populations contained the lowest number of respondents $(0.2 \%, 0.0 \%$ and $0.8 \%$ in LSM groups 3, 4 and 5, respectively, of the white population; $0.5 \%$ and $1.1 \%$ in LSM groups 3 and 4 of the coloured population). This may explain the inconsistent results. Results from the CVD scale showed a possible trend in all four race groups for lower LSM groups to consider the influence of food on cardiovascular health less important than the higher LSM groups. The availability of radios is widespread in LSM groups 2 and 3 ( $80 \%$ and $92 \%$ ), television sets less so at only $30 \%$ and $55 \%$, compared with LSM groups 9 and 10 with nearly $100 \%$ having radios and television sets. These higher LSM groups also have high percentages owning personal computers (access to the Internet) and satellite televi$\operatorname{sion}^{(17)}$. These groups therefore probably have a lot more exposure to health messages from various organisations. This is possibly one of the reasons why the higher LSM groups considered the statements to be more important. It can further be speculated that a higher income and perhaps a higher regard for the importance of health in the higher LSM groups may explain the differences in response. 
The age-standardised mortality rates per 100000 population is 85 for black men, 66 for black women, 323 for white men, 187 for white women, 203 for coloured men, 169 for coloured women, 497 for Indian men and 346 for Indian women ${ }^{(23)}$. Our results also show that whites are over-represented in the upper LSM groups, leading us to speculate that the possible higher risk of CVD in the higher LSM groups could have influenced their beliefs regarding the importance of food on modifying cardiovascular health. It has been shown that risk to health is one of the factors that may influence consumers' responses to acceptance of functional foods ${ }^{(24)}$.

Of the five known risk factors for CVD included in the statements, weight loss and its link to food were believed to be of least importance. Sixty-one per cent of the study population believed that it is important, $21 \%$ believed that it is unimportant and $18 \%$ were undecided whether it is important or not that weight loss can be influenced by eating certain food types; these percentages translating respectively into 6.5 million, 2.2 million and 1.9 million persons in the total population. The response to this statement could have been influenced by the observation, previously made in the literature, that in the black African section of our population there is no social pressure to lose excess weight, especially in the rural areas ${ }^{(25,26)}$. Obesity is, however, a well-established cause of diabetes mellitus, hypertension and lipid abnormalities ${ }^{(27)}$. In a review of published data on mortality from and risk factors of CVD in South Africans, Vorster ${ }^{(2)}$ reported that the prevalence of obesity in black women was higher than in other groups of women, while white men showed the highest prevalence among the male groups. In the THUSA study, a cross-sectional study on the black population of the North West Province of South Africa, obesity was the most important factor associated with elevated total serum cholesterol and low-density lipoprotein cholesterol concentrations during urbanisation $^{(28)}$. In addition, among the women in the THUSA study a high rate of obesity was reported that was associated with an increased risk for non-communicable disease $^{(29)}$. The large number of South African metropolitan adults ( $21 \% ; 2.2$ million) who consider the influence of eating certain food types on weight loss as unimportant is of concern.

Functional foods that are developed for the prevention and treatment of cardiovascular health would perhaps be more successful if targeted at the higher LSM groups and less successful when aimed at weight loss. It is, however, important to take into account that acceptance of functional foods is not only influenced by health beliefs but also by factors such as price, palatability, cultural acceptability and risk of disease ${ }^{(24)}$.

From the observation that the majority of South Africans consider the link between food and CVD to be important, it could be expected that existing programmes in South Africa which promote foods that are good for heart health would be known and used. However, only $35 \%$ of metropolitan South African adults studied agreed with the statement that they look for the Heart Foundation symbol, $46 \%$ disagreed and 19\% were undecided (corresponding to 3.7 million, 4.9 million and 2.0 million, respectively, in the total population). The respondents in the lower LSM groups (1 and 2) as well as the black population group agreed the least with the statement that they looked for the Heart Foundation symbol. Although many of the foods that carry the Heart Foundation symbol are staples such as maize meal, oil and beans, it is possible that lower educational status and lower exposure to heart disease could explain why few respondents from the lower LSM groups ever look for the Heart Foundation symbol.

A similar question regarding a 'cancer symbol' was included in the questionnaire that could serve as validation for the question regarding the Heart Foundation symbol. At the time the questionnaire was administered, there was no 'cancer symbol' on South African products. Twenty-nine per cent of the respondents stated that they look for the Cancer Association symbol. This might be an indication that the respondents did not understand the statement fully or were not being completely honest with their answers. It could, however, also be argued that these statements gave an indication of whether respondents look for any type of 'health symbol'. The data may, therefore, still indicate concern regarding the effectiveness of using 'health symbols', and this needs to be investigated further.

This study has limitations in that all the conclusions made are based on just a few statements about peoples' beliefs. The conclusions are not based on any type of indepth data on this specific topic, such as a group of questions to assess the attitude and other possible related factors such as knowledge and social influence. There is, therefore, a need for additional research, especially into the knowledge and attitudes of the lower socio-economic groups, to be able to develop effective prevention programmes.

In conclusion, CVD is an important cause of morbidity and mortality in South Africa and nutrition plays an important role in its prevention and treatment. This study shows that the metropolitan South African adult population considers the influence on CVD of eating certain food types as important. When compared with HIV/AIDS and cancer, heart disease was considered just as important and by some race groups more important. No differences between beliefs of different gender, race and age groups were seen. There was a tendency for the higher LSM groups within all four race groups to have a stronger belief in the importance of the link between food and CVD than the lower LSM groups. Nutritional education, therefore, needs to be aimed at both genders and all ages of the lower socio-economic groups of South Africa. 
Obesity has been proved a major risk factor for CVD. However, modifying weight loss by eating certain food types was considered less important to participants of this study compared with other risk factors for CVD, despite its high prevalence in South Africa. The South African metropolitan population needs to be made aware of the role of nutrition in weight loss.

The Heart Foundation makes use of the Heart Mark symbol to endorse foods that are suitable as part of the Heart Foundation eating plan. Awareness of the symbol seems to be mainly among the higher LSM groups, which might limit its public health impact in the broader South African population. The possible reasons why such a large percentage of the South African metropolitan adults do not look for the symbol or are undecided about it need to be investigated and addressed.

This study shows that this population considers CVD an important issue and some risk factors are considered more important than others. Prevention programmes promoting a healthy lifestyle, which would address the risk factors associated with CVD, should be received with a positive attitude. This will only be effective if the programmes are aimed at specific LSM groups, through the media they use, addressing products and behaviours they are familiar with.

\section{Acknowledgements}

The authors wish to thank the South African Government's Technology and Human Resources for Industry Programme (THRIP) for financial support.

\section{References}

1. World Health Organization (2003) Diet, Nutrition and the Prevention of Chronic Diseases. Joint WHO/FAO Expert Consultation. WHO Technical Report Series no. 916. Geneva: WHO.

2. Vorster HH (2002) The emergence of cardiovascular disease during urbanisation of Africans. Public Health Nutr 5, 239-243.

3. Bradshaw D, Groenewald P, Laubscher R et al. (2003) Initial burden of disease estimates for South Africa, 2000. $S$ Afr Med J 93, 682-688.

4. Seftel HC, Raal FJ \& Joffee BI (1995) Dyslipidaemia in South Africa. Chronic Diseases of Lifestyle in South Africa, pp. 61-71. Cape Town: Medical Research Council.

5. South African Medical Association and Lipid and Atherosclerosis Society of Southern Africa Working Group (2000) Diagnosis, management and prevention of the common dyslipidaemias in South Africa - clinical guideline, 2000. $S$ Afr Med J 90, 164-168.

6. Grundy SM, Cleeman JI, Merz CN, Brewer Jr HB, Clark LT, Hunninghake DB, Pasternak RC, Smith Jr SC \& Stone NJ; National Heart, Lung, and Blood Institute; American College of Cardiology Foundation; American Heart Association (2004) Implications of recent clinical trials for the National Cholesterol Education Program Adult Treatment Panel III guidelines. Circulation 110, 227-239.
7. Association for Dietetics in Southern Africa (ADSA) Working Group (2000) Position Statement on the dietary management of people with dyslipidaemia (ADSA). $S$ Afr J Clin Nutr 13, 16-22.

8. Vorster HH, Love P \& Brown C (2001) Development of food-based dietary guidelines for South Africa - the process. S Afr J Clin Nutr 14, S3-S6.

9. Steyn K, Steyn M, Swanepoel AS, Jordaan PC, Jooste PL, Fourie JM \& Rossouw JE (1997) Twelve-year results of the Coronary Risk Factor Study (CORIS). Int J Epidemiol 26, 964-971.

10. Heart Foundation of South Africa (2003) The Heart Mark. http://www.heartfoundation.co.za/heartmark.php (accessed May 2006).

11. Sargeant A \& West DC (2001) Direct and Interactive Marketing, 1st ed. Oxford: Oxford University Press.

12. Peltzer K (2000) Health behavior in black South African university students. S Afr J Psychol 30, 46-51.

13. Cody R \& Lee C (1990) Behaviors, beliefs, and intentions in skin cancer prevention. J Behav Med 13, 373-389.

14. Farooqi A, Nagra D, Edgar T \& Khunti K (2000) Attitudes to lifestyle risk factors for coronary heart disease amongst South Asians in Leicester: a focus group study. Fam Pract 17, 293-297.

15. Sloan AE (2004) The top 10 functional food trends 2004. Food Technol 58, 28-51.

16. Verschuren PM (2002) Functional foods: scientific and global perspectives. Br J Nutr 88, S125-S130.

17. South African Advertising Research Foundation (2004) All Media and Products Survey (AMPS) 2003B (CD-ROM). Bryanston: SAARF.

18. Haupt P (2003) The SAARF Universal Living Standards Measure (SU-LSM) - 12 years of continuous development. http://archive.saarf.co.za/lsm-article.htm (accessed May 2006).

19. De Vos AS, Strydom H, Fouche HB \& Delport CSL (2005) Research at Grass Roots. For the Social Sciences and Human Service Professions, 3rd ed. Pretoria: Van Schaik.

20. Babbie E \& Mouton J (2001) The Practice of Social Research. Cape Town: Oxford University Press Southern Africa.

21. Field A (2005) Discovering Statistics using SPSS. London: Sage Publications.

22. Ellis SM \& Steyn HS (2003) Practical significance (effect sizes) versus or in combination with statistical significance ( $p$-values). Manage Dyn 12, 51-53.

23. Bradshaw D, Schneider M, Norman R \& Bourne DE (2006) Mortality patterns of chronic diseases of lifestyle in South Africa. In Chronic Diseases of Lifestyle in South Africa: 1995-2005, pp. 9-22 [K Steyn, JM Fourie and N Temple, editors]. Cape Town: South African Medical Research Council.

24. Frewer L, Scholderer J \& Lambert N (2003) Consumer acceptance of functional foods: issues for the future. $\mathrm{Br}$ Food J 105, 714-731.

25. Mvo Z, Dick J \& Steyn K (1999) Perceptions of overweight African women about acceptable body size of women and children. Curationis 22, June, 27-31.

26. Walker ARP, Adam F \& Walker BF (2001) World pandemic of obesity: the situation in Southern African populations. Public Health 115, 368-372.

27. Manson JE, Tosteson H, Ridker PM, Satterfield S, Hebert P, O'Connor GT, Buring JE \& Hennekens CH (1992) The primary prevention of myocardial infarction. New Engl J Med 326, 1406-1416.

28. Oosthuizen W, Vorster HH, Kruger A, Venter CS, Kruger HS \& de Ridder JH (2002) Impact of urbanisation on serum lipid profiles - The THUSA survey. S Afr Med J92, 723-728.

29. Kruger HS, Venter CS \& Vorster HH (2001) Obesity in African women in the North West Province, South Africa is associated with an increased risk of non-communicable diseases: the THUSA study. Br J Nutr 86, 733-740. 